INDO GLOBAL JOURNAL OF

PHARMACEUTICAL SCIENCES

ISSN 2249- 1023

\title{
Callus Mediated In Vitro Regeneration of Plumbago zeylanica L. and Quantitative Analysis for Plumbagin from Agrobacterium rhizogenes Mediated Hairy Root Culture
}

\author{
Bhanupriya Mishra ${ }^{1,2^{*}}$, Anath Bhandu Das ${ }^{1,3}$ \\ ${ }^{I}$ Department of Agricultural Biotechnology, College of Agriculture, Orissa University of Agriculture and Technology, Bhubaneswar- \\ 751003, Orissa, India \\ ${ }^{2}$ Department of Agriculture and Farmers Empowerment, Govt. Of Odisha, Bhubaneswar, India \\ ${ }^{3}$ Post Graduate Department of Botany, Utkal University, Vani Vihar, Bhubaneswar-751004, India
}

Address for Correspondance: Bhanupriya Mishra, bhanupriyamishra2008@gmail.com ; Anath Bhandu Das, abdas.uubot@gmail.com / a_b_das@hotmail.com

Keywords BAP; Callus Culture; Leaf Explants; HPTLC, IBA, NAA; Plumbagin; TLC.

\begin{abstract}
Plumbago zeylanica L. (White chitrak) is an important herbaceous medicinal plant of the family Plumbaginaceae. The roots of Plumbago contain important secondary metabolite compound i.e. plumabgin which has anticancer property. A protocol for profuse callus induction and in vitro regeneration Plumbago zeylanica was developed from leaf explants in Murashige and Skoog (MS) medium supplemented with different concentration of BAP and NAA. Profuse, compact callus was induced on MS medium supplemented with $2 \mathrm{mg}-1$ each of BAP and NAA. Regeneration of roots from the in vitro grown callus was obtained in MS medium supplemented with $0.5 \mathrm{mg}-1$ IBA. More amount of plumbagin (2.5times) was recorded by TLC and HPTLC methods from hairy roots obtained through Agrobacterium rhizogenes (A4 strains) mediated transformation of $P$. zeylanica $\mathrm{L}$. as compared to the roots of in vivo grown plants. The current research findings revealed for the rapid in vitro regeneration and the potentialities of hairy root cultures of P. zeylanica for the production of important secondary metabolite plumbagin. (C) 2016 iGlobal Research and Publishing Foundation. All rights reserved.
\end{abstract}

Conference Proceedings: International Conference on Advances in Plant and Microbial Biotechnology (PMB2017); JIIT, Noida: February 02-04, 2017

Indo Global Journal of Pharmaceutical Sciences( ISSN 22491023 ; CODEN- IGJPAI; NLM ID: 101610675) indexed and abstracted in EMBASE(Elsevier), SCIRUS(Elsevier),CABI, CAB Abstracts, Chemical Abstract Services(CAS), American Chemical Society(ACS), Index Copernicus, EBSCO, DOAJ, Google Scholar and many more. For further details, visit http://iglobaljournal.com 